\title{
Das práticas sociais ao conteúdo temático: interfaces da intervenção no gênero redação do Enem
}

\author{
Fernanda Fernandes Pimenta de Almeida Lima ${ }^{1}$ \\ Ana Paula de Sousa Bacelar ${ }^{2}$ \\ Programa de Pós-Graduação Lato Sensu em Docência Universitária, Universidade Estadual de Goiás, \\ Inhumas, GO, Brasil
}

\begin{abstract}
Resumo: Este trabalho analisa as propostas de intervenção apresentadas nas redações modelares do Exame Nacional do Ensino Médio (Enem) no ano de 2016. A partir da propositura do tema intolerância religiosa, a interculturalidade é gestada em um contexto de admissão do acirramento das lutas por reconhecimento de identidades e de direitos nas sociedades contemporâneas. $O$ espaço destinado à intervenção emerge como campo de tensão, forjado no embate de forças entre diferentes agentes sociais aos quais é atribuído o papel de dirimir, controlar e aplacar conflitos. Utilizando-nos do aparato teórico-metodológico da Análise do Discurso de matriz francesa, dos pressupostos foucaultianos acerca de poder e discurso, e considerando as peculiaridades do itinerário histórico nacional, pretendemos examinar as ocorrências, a complementariedade de ação e a hierarquização dos agentes atuantes na intervenção e, assim, reconhecer os desdobramentos e as nuanças da complexa trama discursiva formada em torno da convivência e dos intercâmbios culturais no Brasil.
\end{abstract}

Palavras-chave: Redação do Enem; Intolerância Religiosa; Interculturalidade; Discurso.

Title: From Social Practices to the Thematic Content: Interfaces to Writing Gender Intervention Of ENEM

Abstract: This essay aims to analyze the proposals for intervention presented in modeled writing essays in the National Secondary Education Exam (Enem) in the year of 2016. From the proposal of religious intolerance theme, interculturality is born in a context of admission of the intensification of struggles on the recognition of identities and rights in contemporary societies. The space provided for intervention emerge as an area of conflict, whereas the force upshot between social agents are assigned to resolve, control and reassure conflicts. Using the theoretical and methodological approach of the French Discourse Analysis, Foucault's approaches about power and speech, and taking account the peculiarities of the national history, we intend to examine the incidents, the action complementarity and the ranking of the agents that act in the intervention, and thus recognize the impact in the complex reality discursive formed around the coexistence and cultural exchanges in Brazil.

Keywords: Enem essays; Religious intolerance; Interculturality; Speech.

\footnotetext{
${ }^{1}$ Professora do Departamento de Letras da Universidade Estadual de Goiás (Campus Inhumas), Doutora em Linguística e Língua Portuguesa (Universidade Estadual Paulista - Campus Araraquara), Pós-Doutora em Linguística (Universidade Estadual de Campinas). Orcid: https://orcid.org/0000-0002-1924-4780 E-mail: ffpalima@uol.com.br

${ }^{2}$ Professora da Rede Particular de Ensino de Goiânia, Goiás. Especialista em Docência Superior (Universidade Estadual de Goiás - Campus Inhumas). Orcid: https://orcid.org/0000-0002-6962-6816 E-mail: paolabbacelar@gmail.com
} 


\section{Introdução}

Aplicado pela primeira vez em 1998, o Exame Nacional do Ensino Médio (Enem) surgiu com um caráter fundamentalmente diagnóstico, em um contexto de políticas educacionais de direcionamento neoliberal, que se propunham a promover "rupturas" com a ordem até então vigente. Hoje, transcorridas aproximadamente duas décadas desde a sua implementação, salvaguardadas as alterações e as distorções do projeto inaugural, o Enem alcançou projeção nacional, progressivo reconhecimento social e adesão cada vez maior de candidatos. Esse crescimento se deve, em grande parte, à adoção dessa avaliação como principal via de acesso ao ensino superior.

No primeiro ano de realização das provas, após uma intensa campanha midiática, segundo dados do Instituto Nacional de Estudos e Pesquisas Educacionais Anísio Teixeira (Inep), 157 mil concludentes da educação básica efetivaram sua inscrição para as provas. Em 2016, 0 número de candidatos alcançou a surpreendente marca de 6,1 milhões. Na contramão da notável expansão quantitativa, o rendimento verificável nas provas de redação tem caído de modo vertiginoso e aumenta anualmente o montante de textos anulados e/ou zerados.

Frente a números tão expressivos e dado que a pontuação do candidato é hoje condição de ingresso nas universidades, o tema da redação do Enem é alvo de grande expectativa social nos meses que antecedem a sua realização. Por conseguinte, quando convertido em frase-tema da referida prova, determinado assunto ganha visibilidade, acirram-se os debates a seu respeito e, assim, são suscitadas as polêmicas e evidenciados alguns dos preconceitos incrustrados em seu bojo. Ademais, as discussões e os tangenciamentos do tema proposto se estendem durante um período muito além da feitura do exame.

A edição do Enem de 2016 trouxe como tema "Caminhos para combater a intolerância religiosa no Brasil". De acordo com o Ministério da Educação, apenas 77 textos alcançaram nota 1000, em contrapartida, 291.806 redações foram anuladas ou obtiveram nota zero. Esse levantamento surpreende pelo aparente despreparo dos candidatos no trato do assunto problematizado.

Ao trazer à discussão a intolerância religiosa, um impasse secularmente dissimulado pelo mito da democracia racial e do melting pof (caldeirão cultural), o Enem destaca a interculturalidade na perspectiva da conflitividade. Além disso, incluindo na frase-tema a sugestão de proposição de medidas resolutivas, já exigidas na arquitetura do texto dissertativoargumentativo pela competência 5 (que avalia a capacidade do candidato de elaborar uma proposta de intervenção para o problema abordado, respeitando os Direitos Humanos), o exame possibilita reconhecer os lugares de poder convencionalmente atribuídos aos mais diversos agentes sociais. 
Vale salientar que são as crenças de matriz africana o principal alvo de ideologias e de atitudes que incitam o ódio e que ferem o princípio da igualdade e da dignidade humana. Segundo dados divulgados pelo Governo Federal, através do canal Disque 100, foram registrados, em 2011, 15 casos de intolerância religiosa. Em 2016, o total de denúncias somou 776 , das quais $25 \%$ eram dirigidas a praticantes do candomblé e da umbanda. Essa problemática está diretamente relacionada ao próprio itinerário histórico nacional e às relações étnico-raciais brasileiras. A "demonização" e a perseguição a umbandistas e candomblecistas reacendem os debates sobre o racismo e evidenciam o falseamento no trato da questão racial. Assim, "o que ora se apresenta como um fenômeno de rejeição às religiões de matriz africana, corresponde à negação da identidade negra no Brasil" (SILVA; SOARES, 2015, p. 5).

Tal como postulado por Foucault (2002), discursos correspondem a práticas sociais determinadas no tempo e delimitadas no espaço, ou seja, elementos integrantes dos diversos processos históricos. Logo, os discursos em circulação sobre religiosidade forjam um dos sustentáculos da assimetria das relações de poder na sociedade e acabam por justificar ações como abuso, dominação, marginalização, discriminação, exclusão e violência.

Considerando, pois, que as redações produzidas pelos candidatos representam a materialidade de discursos em âmbito social, histórico, cultural e ideológico, o cerne desta pesquisa parte da análise de como a prova de redação do Enem, ao dialogar com temas transversais, como o proposto em 2016, convoca seus autores a compreenderem a responsabilidade social dos sujeitos sobre as formas de intervenção política, pessoal e coletiva nos conflitos que permeiam o contexto nacional.

Para tanto, por meio do método de análise documental, de cunho qualitativointerpretativo, examinaremos oito redações modelares apresentadas no Manual do Candidato - Matriz de Redação / Enem 2017. Embasando-nos nos apontamentos teóricos sobre discurso e poder, cunhados das obras $A$ arqueologia do Saber (2002), A ordem do discurso (2006) e $O$ sujeito e o poder (1995), escritas por Michel Foucault, tencionamos realizar uma reflexão sobre os discursos e os seus entrecruzamentos resultantes das práticas sociais na contemporaneidade.

Nas palavras de Maurice Blanchot (1986, p. 27-28), A arqueologia do saber e A ordem dos discursos marcam

[...] o período - o fim do período - em que Foucault, escritor que era, pretendeu pôr a descoberto práticas discursivas quase puras, no sentido em que não remetiam senão para si próprias, para as suas regras de formação, para o seu ponto de fixação, ainda que sem origem, para a sua emergência, ainda que sem autor, para um trabalho de decifração que nada revelaria de oculto [...]. 
Neste sentido, as práticas discursivas não se reduzem à expressão individual dos sujeitos, mas consistem em "um conjunto de regras anônimas, históricas, sempre determinadas no tempo e no espaço, que definiram, em uma dada época e para uma determinada área social, econômica, geográfica ou linguística, as condições de exercício da função enunciativa" (FOUCAULT, 2002, p. 136). Tentamos, assim, perscrutar as regularidades enunciativas, inscritas em redações do Enem, que dão voz às diferenças (des)alinhadas nas relações interculturais. Observamos os efeitos de sentido que urdem práticas sociais, regulamentadas historicamente e mobilizadas nos discursos aqui assentados em redações do Enem. Estes mobilizam uma singular relevância atribuída aos efeitos das práticas que engendram o poder e os sujeitos na sociedade atual.

\section{Interculturalidade, religião e a cena brasileira}

Vivemos uma época marcadamente contraditória. É tempo de dominância do ideal da "Comunidade Global", uma configuração pretensamente capaz de promover o adensamento do mundo, a eliminação de fronteiras e o esgotamento de antigos antagonismos. Paradoxalmente, as barreiras nacionais, geográficas, étnico-raciais, religiosas e ideológicas estão notadamente presentes na mídia, nos expedientes legais de fechamento territorial e nos recentes planos governamentais apresentados em diversos países do globo. Desse contexto, repleto de ambivalências e de perspectivas aparentemente inconciliáveis, aflora o conceito da interculturalidade.

Candau (2015) assevera que, embora os termos multiculturalismo e interculturalismo sejam recorrentemente entendidos como sinônimos, há uma representativa dissociação conceitual entre eles. O multiculturalismo, grosso modo, corresponde à tomada de consciência quanto à presença de diferentes grupos sociais numa mesma sociedade. Já o interculturalismo supõe a deliberada interrelação entre essas diferentes culturas. Assim, "a consciência do caráter multicultural de uma sociedade não leva espontânea e necessariamente ao desenvolvimento de uma dinâmica social informada pelo caráter intercultural" (CANDAU, 2015, p. 06).

Para Walsh (2001), a interculturalidade é um processo dinâmico, uma tarefa social e política e, em essência, um espaço de negociação onde os conflitos de poder da sociedade não são mantidos ocultos e sim reconhecidos e confrontados. Nesse mesmo passo, Rodrigues (2007) defende que a questão intercultural não pode ser examinada sem o devido referimento às lutas por reconhecimentos de identidades e de direitos. Isso, de certo modo, instaura fronteiras, fixa valores, ancora uma pseudo estabilidade que, em seu esteio, promove contendas e gera resistências. 
Quanto ao embate entre identidade e violência, Sen (2015, p. 21) declara que

[...] um sentimento de identidade pode ser uma fonte não só de orgulho e alegria, mas também de força e segurança. [...] E, no entanto, a identidade também pode matar - e matar com desembaraço. Um forte - e exclusivo sentimento de pertencer a um grupo pode, em muitos casos, conter a percepção da distância e da divergência em relação a outros grupos. A solidariedade dentro de um grupo pode ajudar a alimentar a discórdia entre grupos.

Assim, a experiência cotidiana da interculturalidade, longe de pressupor uma realidade homogênea, pauta-se na consciência da permanente troca, dos constantes contratos, das inevitáveis contestações e da necessária revisão de princípios da vida coletiva, muitas vezes, difíceis de equacionar.

A intersecção entre religião e cultura que marca o contexto contemporâneo das relações humanas é ponto nevrálgico dessa discussão. Embora o Brasil seja um país oficialmente laico e ainda que a Constituição Federal de 1988 disponha, no inciso VI de seu art. 5o, que a liberdade de consciência e de crença é um direito inviolável, assegurando a todos os brasileiros o livre exercício de cultos religiosos e garantindo a proteção aos seus locais de culto e às suas liturgias, são cada vez mais recorrentes as manifestações de intolerância, em especial, dirigidas aos cultos de crença afro-brasileira.

Apesar de os dispositivos jurídico-normativos nos planos nacional e internacional combaterem as práticas de violência em nome da religião, as constantes notícias de manifestações contra esculturas de orixás expostas em áreas públicas, a invasão e a depredação de terreiros, o ataque e a destruição de imagens e até mesmo os espancamentos de praticantes dos cultos afro-brasileiros desvendam a falácia do famigerado sincretismo orgânico tradicionalmente associado à cena brasileira.

Segundo Oliveira (2015, p. 47),

[...] A crença de que o Brasil é uma sociedade mestiça levou à adoção de medidas e políticas ambíguas. Exatamente aí se encontra a discussão sobre etnicidade. A crença na mestiçagem, isto é, de que somos o resultado de uma mistura, de uma hibridização, levou as pessoas a não repararem nas diferenças étnicas e em outros sistemas de valores. Nesta situação, negros, índios e outras minorias étnicas com suas culturas, religiões e costumes são considerados peças imóveis de um mosaico social e suas especificidades culturais seriam apenas um fato aceito como tal. 
Nas sociedades contemporâneas, os indivíduos interiorizam formas e conteúdos culturais plurais e até mesmo antagônicos entre si. Analisando o percurso brasileiro, evidenciase, em diferentes momentos históricos, o uso de inúmeras estratégias de contenção de movimentos e de negação de conflitos, tais como o racismo e a intolerância religiosa. Encoberta pelo véu da democracia racial e do sincretismo religioso, repousa uma tradição de dissimulação e de sufocamento, gestada em um contexto discursivo de atenuação e regida por domínios institucionais implícitos.

Dado que a liberdade religiosa e a preservação das identidades socioculturais constituem uma forma de resistência ao modo de pensar e agir hegemônico e excludente (SILVA; SOARES, 2015, p. 4), reconhecer a persistência da discriminação e a necessidade de promoção do comportamento tolerante é, pois, fundamental.

Ainda sobre os aspectos específicos do contexto nacional no que tange à interculturalidade, Fleuri (1999, p. 284) observa que

[...] na realidade brasileira, a dimensão intercultural se reveste de significados específicos. Colonialismos e migrações, dominações e convivências têm induzido profundos processos de aculturação: fusões sincréticas e violentas, perdas de identidade cultural encontram-se na própria formação da sociedade brasileira.

A complexidade da "intercultura" no Brasil exige que as incursões a seu respeito sejam postas em um quadro de referências mais amplo, capaz de alcançar diferentes campos de reflexão e de considerar a multiplicidade e as contrariedades a ela inerentes. Eis um terreno fértil do ponto de vista linguístico e propício para a intervenção da Análise do Discurso de linha francesa (doravante $A D$ ). Como disciplina de entremeio, suas formulações intervalares sobre discurso permitem mais do que uma análise textual, ocasionando um entendimento contextual da estrutura discursiva em questão. À vista disso, promove um melhor entendimento das ideologias que permeiam a construção dos textos e a influência do contexto político-social em sua produção.

O francês Michel Foucault dedicou parte dos seus estudos à contemplação das batalhas por soberania e busca pelo subjugo que marcam a trajetória histórica da humanidade. Para ele, a história das raças e do enfrentamento permanente das raças emerge como uma contrahistória, é o discurso da ruptura no qual a memória ganha um novo sentido, dilacerando a sociedade e reivindicando direitos. Embora não corresponda com exatidão a uma "teoria do poder", os postulados de Foucault sobre discurso e poder são fundamentais à compreensão dos processos de "naturalização" da inferioridade e de ascensão do racismo moderno e das práticas de intolerância dirigidas às religiões de matriz africana. 
Saliente-se ainda que a análise das formas de exercício do poder materializadas nas redações do Enem tem, na proposta de intervenção, o espaço por excelência para reconhecimento de como se dá a escolha e a organização dos agentes sociais responsáveis pela intermediação dos conflitos interculturais. Não se trata apenas de reconhecer os agentes citados ou preteridos, quantificá-los e mapeá-los, mas sim de avaliar em que medida uns contribuem, estruturam e limitam o campo de possível ação dos outros. Afinal, retomando Foucault (1995, p. 242), o exercício do poder não é simplesmente uma relação entre "parceiros" individuais ou coletivos, é um modo de ação de alguns sobre outros.

\section{Redação do Enem: um gênero, alguns discursos}

As modernas concepções sobre a linguagem ganham especial impulso nos estudos desenvolvidos, no século XX, pelo filósofo russo Mikhail Bakhtin. Ultrapassando a ideia da língua como sistema autônomo, o estudioso enfatiza que "só há língua onde há interação". A partir, pois, de uma perspectiva dialógica da linguagem, os pressupostos bakhtinianos asseveram que "cada esfera de utilização da língua elabora seus tipos relativamente estáveis de enunciados, sendo isso que denominamos gêneros do discurso" (BAKHTIN, 1992, p. 279).

No que tange à heterogeneidade dos gêneros do discurso, Bakhtin (1992, p. 280) diz que

[...] A riqueza e a variedade dos gêneros do discurso são infinitas, pois a variedade virtual da atividade humana é inesgotável, e cada esfera dessa atividade comporta um repertório de gêneros do discurso que vai diferenciando-se e ampliando-se à medida que a própria esfera se desenvolve e fica mais complexa.

É nesse quadro de possibilidades e de diferentes demandas que a redação do Enem emerge com o status de um gênero discursivo, visto que se constitui a partir de determinadas práticas sociais, organiza-se numa forma e num estilo que atende à exigência institucional, relacionando-a às determinações estruturais. Cumpre, pois, os três aspectos básicos da concepção de gênero, a saber: o tema (conteúdo temático), a estrutura (plano composicional) e o estilo (forma particular de escrita).

Na apresentação do Manual do Candidato do Enem, todavia, à guisa de orientação geral, as expectativas quanto à redação são assim definidas:

A prova de redação exigirá de você a produção de um texto em prosa, do tipo dissertativo-argumentativo, sobre um tema de ordem social, científica, cultural ou política. Os aspectos a serem avaliados relacionam-se às competências que 
devem ter sido desenvolvidas durante os anos de escolaridade. Nessa redação, você deverá defender uma tese - uma opinião a respeito do tema proposto -, apoiada em argumentos consistentes, estruturados com coerência e coesão, formando uma unidade textual. Seu texto deverá ser redigido de acordo com a modalidade escrita formal da língua portuguesa. Você deverá, também, elaborar uma proposta de intervenção social para o problema apresentado no desenvolvimento do texto que respeite os direitos humanos.

Cônscios de que o enunciado verbal é produzido dentro de um contexto social, histórico, cultural e ideológico e, por conseguinte, materializa, reproduz, replica e promove sofismas e significações estabilizadas, salientamos que, ao definir, a priori, que o candidato desenvolva um texto dissertativo-argumentativo em prosa, o Manual de Redação do Enem apresenta uma concepção de gênero extremamente generalista. Essa caracterização inicial mostra-se, assim, insuficiente para constituir o gênero discursivo redação do Enem.

Para Morato e Prado (2016, p. 2016),

[...] o que faz a redação do ENEM se configurar como um gênero textual não é apenas a evidência de que estamos tratando de uma possibilidade de se considerar a língua em uso para fins que atendam a determinada demanda social, que, no caso do ENEM, podem ser o ingresso em uma universidade ou a conclusão do ensino médio, por exemplo. Estamos lidando com um tipo de texto que solicita ao enunciador uma apreciação crítica, uma opinião e uma proposta de solução para um problema social.

Conforme exposto, a proposta de intervenção na redação do Enem tem importância capital para o seu enquadramento como gênero do discurso. Depreendem-se daí algumas condições de produção que embasam a construção do gênero redação do Enem que, em linhas gerais, caracteriza-se como um texto relativamente conciso, cuja estrutura dissertativoargumentativa materializa conteúdos temáticos que convocam seus autores a inscreverem na construção textual o seu lugar de sujeito. Considerando que "o discurso não é o lugar de irrupção da subjetividade pura; é um espaço de posições e funcionamentos diferenciados para os sujeitos" (FOUCAULT, 2010, p. 8), a subjetividade nesse gênero se inscreve em linhas e desloca-se entre elas, interpelando o território, a raça, a religião, a cultura, a sociedade e a história que lhe dão voz.

Ademais, enquanto a tese e a argumentação são componentes comuns aos textos da tipologia dissertativa, a obrigatoriedade de intervir constitui um traço particular da estrutura composicional do mencionado gênero. Por fim, vale destacar que é na avaliação da recorrência, da hierarquização e da complementariedade de ação dos agentes atuantes na intervenção que repousa o interesse precípuo da presente pesquisa. 


\section{Proposta de intervenção: uma zona de conflito}

Diante da prova de Redação do Enem, um dos maiores desafios enfrentados pelos candidatos é o atendimento à competência $V$, que requer a elaboração de proposta de intervenção, detalhada e articulada à discussão desenvolvida no texto. Além de avaliar a exequibilidade da intervenção, urge ainda que seu propositor tenha em mente o respeito aos direitos humanos, compreendidos, nos termos do exame, como o não rompimento com os valores de cidadania, liberdade, solidariedade e diversidade cultural.

A discussão em torno da concepção de direitos humanos na Redação do Enem ganhou progressivo acirramento nos últimos anos. Em 2016, diante do argumento de que esse conceito não era suficientemente claro, o Inep definiu mais objetivamente sua percepção no Manual do Candidato. No ano de 2017, os questionamentos seguiram e o Superior Tribunal Federal (STF) determinou a exclusão do item do edital que definia nota zero para o desrespeito aos direitos humanos. Não houve, no entanto, nenhuma modificação na competência $V$. A retirada definida pelo STF foi realizada então no edital de 2018.

As implicações dessa mudança no campo linguístico são inúmeras. O discurso, anteriormente interditado, do direcionamento em favor da crença pessoal do candidato, por exemplo, no caso da explanação sobre intolerância religiosa, é agora autorizado. E o principal argumento, amplamente divulgado nas mídias sociais pelo Movimento Escola Sem Partido, que liderou a anulação da impostura dos direitos humanos na redação do Enem, é que o indivíduo não pode ser penalizado por questões "meramente" ideológicas em defesa do que se considera "politicamente correto".

Ainda em relação à competência $V$, orienta o Inep (2017, p. 24) que

[...] A proposta de intervenção deve refletir os conhecimentos de mundo de quem a redige e, quando muito bem elaborada, deve conter não apenas a exposição da ação interventiva sugerida, mas também o ator social competente para executá-la, de acordo com o âmbito da ação escolhida: individual, familiar, comunitário, social, político, governamental e mundial.

Nesse processo, os textos motivadores presentes na coletânea têm considerável relevância, pois, ao apontarem os caminhos que o candidato pode tomar na abordagem do tema, sugerem, por conseguinte, os agentes que atuarão na intervenção. Se considerarmos especificamente a prova de 2016, quando foi proposto o tema "Caminhos para combater a intolerância religiosa no Brasil", constataremos que, dos quatro textos apresentados, três deles estão relacionados a dispositivos jurídico-normativos e um aponta para o maior índice de 
discriminação aos praticantes de religiões afro-brasileiras. Destarte, há um pendor para a adoção de medidas institucionalizadas geridas por instâncias governamentais.

No que tange à organização estrutural do Manual de Redação do Enem, na primeira seção, cada uma das competências é conceituada e os critérios para a correção do exame são definidos. Já a segunda seção, intitulada Amostra de redações nota 1000 do Enem 2016, é constituída por produções que cumpriram todas as exigências relativas às cinco competências. Nesta parte do material, constam: a reprodução dos textos motivadores constantes na prova, a identificação do candidato, a transcrição do seu texto e, por fim, os comentários concernentes ao desempenho em cada competência. Quanto à proposta de intervenção, em todos os comentários registrados, há o destaque à concretude, ao detalhamento e ao respeito aos direitos humanos nas ações interventivas.

Nos oito textos divulgados na seção de amostras de redações nota 1000 do Manual do Participante 2017, a ocorrência dos agentes de intervenção apresenta o Estado como agente de intervenção por excelência, o que Ihe permite reger, definir, organizar e até mesmo limitar a ação dos demais interventores que são referidos, em alguns textos, como "parceiros" e não como protagonistas no combate à intolerância religiosa.

Sobre a concepção de Estado, este é equiparado a um sistema complexo, dotado de aparelhos múltiplos, que tem por função constituir o invólucro geral, a instância de controle global, o princípio de regulação e, até certo ponto, também, de distribuição de todas as relações de poder num conjunto social dado (FOUCAULT, 1995, p. 246).

Logo, do ponto de vista conceitual, Estado e Governo possuem diferentes acepções. O Estado é o conjunto de instituições públicas que representam e atendem aos anseios da população de determinado território. O governo, por sua vez, é apenas uma das instituições que compõem o estado. Nos textos em análise, todavia, há ocorrências de Governo e Estado sendo utilizados como termos permutáveis.

Nessa altura da discussão, cabe ressaltar uma vez mais que Foucault não se propôs a elaborar uma teoria do poder, mas, em seus apontamentos, contribui enormemente ao subverter a concepção tradicional das ciências sociais, propondo que o poder não está nas instituições. Para o estudioso, o poder é uma prática social historicamente construída. Mesmo afirmando que o poder não se encerra na esfera estatal, estando "dissolvido" no tecido social, destaca que "o Estado nas sociedades contemporâneas não é simplesmente uma das formas ou um dos lugares - ainda que seja o mais importante - de exercício do poder, mas que de um certo modo, todos os outros tipos de relação de poder a ele se referem" (FOUCAULT, 1995, p. 247).

Dentre as propostas de intervenção apresentadas, apenas uma delas sugere a experiência cotidiana da interculturalidade num viés decolonial, ou seja, diverso do ideal cultural eurocêntrico e homogêneo. Para tanto, recomenda que 
[...] A fim de garantir, portanto, a equidade na garantia de direitos à população, são necessárias transformações na sociedade brasileira. O Ministério da Educação, primeiramente, deve inserir à matriz curricular estudantil debates e estudos antropológicos acerca do processo de formação do país, de modo a valorizar a participação das mais variadas culturas na composição da identidade brasileira. (INEP, 2017, p. 31)

Essa abordagem coaduna-se com os pressupostos para a superação de uma tradição conservadora e monocultural, situando a escola como possibilitadora de contextos educativos diversos em subjetividades sociais e culturais. Ao elaborar tal proposta, a candidata reconhece a necessidade de legitimação e do estabelecimento de contratos e de negociações para a coexistência de matrizes culturais diversas. Nestes termos, aponta

[...] para a compreensão e construção de processos educativos em que diferentes sujeitos constituem sua identidade, elaborando autonomia e consciência crítica, na relação de reciprocidade (cooperativa e conflitual) com outros sujeitos, criando, sustentando e modificando metacontextos, na direção de uma "ecologia da mente". (FLEURI, 1999, p. 287)

Em seu texto, a autora, embora considere uma medida resolutiva que traz em seu bojo o princípio da diversidade e o respeito à diferença, atribui a uma instituição estatal a função de agente responsável pela implementação da devida medida.

Em um outro texto modelar, é sugerida a adoção de uma política de ação afirmativa, ou seja, de uma medida pública de caráter compulsório, facultativo ou voluntário, visando a mitigar os efeitos da discriminação e a promover a efetiva igualdade. Nele, a autora defende

[...] a criação de cotas, ação que deve ser feita pelo poder público, que garantam a presença de representantes das diversas expressões religiosas na política, o que permitiria a aprovação de medidas afirmativas que reduziriam a intolerância no Brasil. (INEP, 2017, p. 43)

Ainda que, uma vez mais, se eleja o Estado como agente, essa medida difere das demais por ultrapassar o caráter meramente proibitivo e punitivo característico da intervenção estatal. Trata-se da promoção de maior representatividade de um grupo minoritário nas esferas públicas, o que corrobora com as ditas políticas de discriminação positiva.

Em uma outra produção, a candidata propõe que

[...] Por tudo isso, é imprescindível que todos os segmentos sociais unam-se em prol do combate à intolerância religiosa no Brasil. Assim, cumpre ao governo efetivar de maneira mais plena as leis existentes. Ademais, cabe às escolas e às 
famílias educarem as crianças para que, desde cedo, aprendam que têm o direito de seguir suas escolhas, mas que devem ser tolerantes e respeitar as crenças do outro. Afinal, como disse Nelson Mandela, 'a educação é a arma mais poderosa para mudar o mundo'. (INEP, 2017, p. 35)

Percebemos que, embora a autora defenda uma ação conjunta de "todos os segmentos sociais" no combate à intolerância religiosa, em sua perspectiva, o governo e as leis comandam o ordenamento de medidas interventoras. Os sujeitos autores, aqui, ao participarem da cena discursiva do Enem, reconhecem a existência de regras que servem de invólucro a um sistema de relações constitutivas dos enunciados sobre medidas intervenção. Daí, identificarmos nos textos a ação do Estado e os sentidos que desta emanam com uma dada regularidade, uma marca comum, o que é significativo a uma concepção de intervenção que, copiosamente, se sobrepõe às outras possíveis.

Além da prevalência do Estado, embora variadas em suas formas de ação, as medidas de intervenção propostas nos textos modelares, apontam dois caminhos recorrentes: a conscientização mediada e, em larga escala, a ação disciplinadora e punitiva dos agentes interventores, conforme explicitam os seguintes excertos:

Conclui-se, então, que o combate à discriminação religiosa é de suma importância para que se assegure um dos direitos mais antigos a todas as pessoas e, por conseguinte, seu bem-estar. Para isso, é preciso que os órgãos especializados, em parceria às delegacias de denúncia, ajam de acordo com a lei, investigando e punindo os agressores de forma adequada. (INEP, 2017, p. 31)

Diante disso, para combater a intolerância religiosa, cabe ao Governo intensificar esforços, criando leis específicas e aumentando o tempo de punição para quem comete qualquer tipo de violência devido à religião. (INEP, 2017, p. 32)

A atuação estatal, além de promover a criação de leis específicas e a ampliação do tempo de punição, conduziria a abertura de novos canais de denúncia e de postos policiais, a investigação de casos de impunidade e a criação de delegacias especializadas em crimes que envolvam intolerância religiosa.

Com base nos textos produzidos pelos candidatos que alcançaram nota máxima e que, por isso, são apresentados como modelos para produções futuras, sobre intolerância religiosa, uma problemática secularmente sedimentada no cenário nacional, a disciplina promovida pelo Estado é legitimada como principal via de superação.

Neste ponto, os discursos materializados pelos candidatos se relacionam com a descrição dos mecanismos de uma microfísica do poder feita pelo próprio Foucault (2004), em que ele expõe que a disciplina se vale da vigilância hierárquica e da sanção normalizadora a fim 
de garantir a segurança. Essas relações de poder estão tão enraizadas na rede social e no imaginário coletivo que, diante da necessidade de criação de uma proposta exequível e eficiente no enfrentamento de conflitos, a punição é a medida mais corrente e o Estado ganha status de agente interventor por excelência ao qual é atribuída uma espécie de "poder fundamental", que gere e que submete os demais atores sociais.

\section{Considerações finais}

Este estudo tentou perscrutar algumas possibilidades de análise enunciativa sobre os conflitos interculturais e os efeitos de sentidos deles provenientes e materializados nos discursos produzidos nos textos do gênero redação do Enem 2016. Ao problematizar temas de escopo polêmico, como a intolerância religiosa, a referida prova declara o propósito de estimular o pensamento crítico e de avaliar a capacidade argumentativa dos candidatos. Todavia, ao fazê-lo sob um regime de regras e interdições, em um exame de alta expectativa social, acaba por promover um simulacro de posicionamentos que nem sempre refletem as reais concepções do autor, haja vista as condições de produção que norteiam os candidatos.

$\mathrm{Na}$ presente abordagem, ao considerarmos o quadro composicional do gênero em estudo, optamos pela contemplação da competência $V$, que sugere a elaboração de uma proposta de intervenção com medidas, ações e agentes bem definidos e articulados com a discussão promovida nas demais seções do texto. Dentre os elementos da intervenção, escolhemos os agentes interventores como alvo principal da nossa análise por entendermos que a seleção, a organização e a distribuição de responsabilidades entre eles refletem, em grande medida, as relações de poder estabelecidas na contemporaneidade.

Durante a análise, a predominância da ação estatal na propositura das medidas de caráter punitivo, associada ao direcionamento jurídico-normativo amparado pelos textos motivadores e legitimada pela adoção dos textos com esses vieses, como modelos no Manual do Candidato, delineia um campo de tensão constituído por discursos entrecruzados sobre religião, raça e poder. Tais discursos relacionam-se nos textos embasando a produção de sentidos que dão voz às relações interculturais e, ao mesmo tempo, conflituosas na sociedade atual.

Ao se atribuir ao Estado as maiores possibilidades de intervenção ou de resolução ao problema proposto, adverte-se, em termos, que há uma "consciência" social ainda hesitante e escusa. Neste sentido, há matizes diversos que precisam ser considerados, a fim de compreendermos o que possibilita que, em tempos de crise e de descrédito das instituições estatais, sobre elas ainda repousem as maiores expectativas resolutivas dos conflitos sociais historicamente constituídos. 


\section{Referências}

BAKHTIN, Mikhail Mikhailovich. Os gêneros do discurso. In: BAKHTIN, Mikhail Mikhailovich. Estética da criação verbal. São Paulo: Martins Fontes, 1992. p. 277-326. Original publicado em 1952-53.

BLANCHOT, Maurice. Foucault como o imagino. Lisboa: Relógio D’Água, 1986.

BRASIL. Cartilha do Participante: ENEM. 2017. Disponível em: <http://download.inep.gov.br/educacao_basica/enem/guia_participante/2017/manual_de_red acao_do_enem_2017.pdf>. Acesso em: 15 mai. 2018.

BRASIL. Constituição (1988). Constituição da República Federativa do Brasil. Brasília, DF: Senado Federal: Centro Gráfico, 1988.

CANDAU, Vera Maria F. Interculturalidade e educação escolar. Disponível em: <http: //www.dhnet.org.br/direitos/militantes/veracandau/candau_interculturalidade.html>. Acesso em: 10 abr. 2018.

FLEURI, Reinaldo Matias. Educação intercultural no Brasil: a perspectiva epistemológica da complexidade. Revista Brasileira de Estudos Pedagógicos, Brasília, v. 80, p. 277-289. 1999.

FOUCAULT, Michel. A arqueologia do saber. 6. ed. Tradução de Luís Felipe Baeta Neves. Rio de Janeiro: Forense Universitária, 2002.

FOUCAULT, Michel. A ordem do discurso. 13. ed. Tradução de Laura Fraga de Almeida Sampaio. São Paulo: Edições Loyola, 2006.

FOUCAULT, Michel. Microfísica do poder. Tradução de Roberto Machado. 19. ed. Rio de Janeiro: Edições Graal, 2004.

FOUCAULT, Michel. O sujeito e o poder. In: DREYFUS, Hubert; RABINOW, Paul. Michel Foucault: uma trajetória filosófica. Rio de Janeiro: Forense Universitária, 1995. p. 231-249.

FOUCAULT, Michel. Resposta a uma questão. FOUCAULT, Michel. Repensar a política. Ditos e escritos VI. Tradução de Ana Lúcia Paranhos Pessoa. Rio de Janeiro: Forense Universitária, 2010. p. 01-23.

MORATO, Rodrigo A.; PRADO, Daniela de Faria. A redação do ENEM como gênero textual discursivo: uma breve reflexão. Cadernos ESPUC, n. 29, 2016. https://doi.org/10.5752/P.23583231.n29p205-219

OLIVEIRA, Irene Dias de. Religião e as teias do multiculturalismo. São Paulo: Fonte Editorial, 2015.

ORLANDI, Eni. Análise de discurso. 5. ed. Campinas, SP: Pontes, 2003.

RODRIGUES, Maria Beatriz. Interculturalidade: por uma genealogia da discriminação. Psicologia \& Sociedade [online]. 2007, v. 19, n. 3, p. 55-61. https://doi.org/10.1590/S0102$\underline{71822007000300009}$ 
SEN, Amartya. Identidade e violência: a ilusão do destino. São Paulo: Iluminuras: Itaú Cultural, 2015.

SILVA, Lucilia da; SOARES, Katia. A intolerância religiosa face às religiões de matriz africana como expressão das relações étnico-raciais brasileiras: o terreno do combate à intolerância no município de Duque de Caxias. Revista EDUC, v. 1, n. 3, 2015.

WALSH, Catherine. La educación intercultural en la educación. Peru: Ministerio de Educación, 2001. Mimeografado. In: CANDAU, Vera (Org.). Diferenças culturais e educação: construindo caminhos. Rio de Janeiro: 7 Letras, 2011. 212p.

Recebido em: 11/08/2018

Aceito em: $29 / 12 / 2018$ 